Bol. Mus. Para. Emilio Goeldi. Ciências Naturais, Belém, v. 1, n. 2, p. 65-78, maio-ago. 2006

\title{
Castanheira-do-brasil recuperando áreas degradadas e provendo alimento e renda para comunidades da Amazônia Setentrional ${ }^{1}$

\author{
The role of Brazil nut trees in restoring degraded forest areas and as a source of \\ food and income for northern Amazonian communities
}

\author{
Rafael de Paiva Salomão ${ }^{\mathrm{I}}$ \\ Nélson Araújo Rosa ${ }^{\mathrm{I}}$ \\ Alexandre Castilho II \\ Kácio Andrey Câmara Morais II
}

Resumo: A castanheira-do-brasil (Bertholletia excelsa H. \& B. - Lecythidaceae) é a espécie de maior diâmetro entre todas as demais da floresta amazônica. Árvores com 5,25 m e 4,34 m de diâmetro a 1,3 m do solo (DAP) já foram registradas, assim como a ocorrência, em um mesmo local, de mais de dez castanheiras com diâmetros superiores a $3 \mathrm{~m}$. Existem fortes evidências de que alguns exemplares de castanheira possam ser milenares e ainda produtivos. Este trabalho objetivou informar como se comporta a castanheira no que tange aos crescimentos do diâmetro e da altura em reflorestamentos heterogêneos que visam a recuperar áreas degradadas pela atividade de mineração na Floresta Nacional Saracá-Taqüera, Instituto Brasileiro do Meio Ambiente e dos Recursos Naturais Renováveis (IBAMA) em Porto Trombetas, estado do Pará e, também, avaliar qual é a produção de um castanhal primitivo, em termos de safra e renda, para uma comunidade de castanheiros daquela região. Numa área de 19,4 ha, reflorestada em 1984 com diversas espécies florestais, foram registradas e medidas (diâmetro e altura) todas as 482 castanheiras ali plantadas. Para avaliar a safra de castanha foi implantado, numa Reserva de Castanheiras dentro da Flona, um estudo para quantificação e pesagem de ouriços e castanhas das safras de 2003 a 2007. Foram registradas 482 castanheiras (= 24,8 árvores/ha). O menor diâmetro foi de 2,1 cm e o maior de 61,6 cm $(=19,4 \mathrm{~cm})$, gerando um incremento médio de 1,02 cm/ano; a amplitude do incremento variou de 0,11 cm/ano até $3,24 \mathrm{~cm} / \mathrm{ano}$; a menor altura total foi de $3 \mathrm{~m}$ e a maior de $28 \mathrm{~m}$ (=14,7 m). Conseqüentemente, o incremento médio foi de 0,77 m/ano - mínimo de $0,16 \mathrm{~m} / \mathrm{ano}$ e máximo de 1,47 m. Para estimação a produção de ouriços e castanhas foram avaliadas 84 árvores com diâmetros variando desde $48 \mathrm{~cm}$ até $226 \mathrm{~cm}(=122 \mathrm{~cm})$ e abundância de 14 castanheiras/ha, excepcionalmente altas. $\mathrm{Na}$ safra de castanha de 2003, 74 castanheiras produziram frutos (= 29 ouriços/castanheira). Cada ouriço tinha em média 16 castanhas (peso médio unitário de $7 \mathrm{~g}$ ). A produção média foi de 477 castanhas/árvore, o que representou uma safra baixa. Uma safra normal na região produz 800 hectolitros, correspondentes a $34,000 \mathrm{~kg}$, que comercializados rendem $\mathrm{R} \$ 68.000,00$ (US\$22,666.67). Divididos pelos 30 coletores, resulta em $\mathrm{R} \$ 2.267,00$ (US\$755.67) por trabalhador para os três meses de serviço (fevereiro, março e abril), ou R\$756,00 (US\$252.00) por mês para cada trabalhador se a divisão fosse igualitária, o que, é sabido, não acontece, pois deste valor mensal o coletor recebe menos de 40\%, próximo de $\mathrm{R} \$ 300,00 / \mathrm{mês}$ (US\$100.00). A castanheira-do-brasil, plantada em áreas degradadas da Amazônia setentrional, através de reflorestamentos heterogêneos, é uma espécie de comprovada adaptabilidade e excelente crescimento. Uma seleção da matriz de sementes possibilita a obtenção de árvores com $60 \mathrm{~cm}$ de diâmetro e altura de $28 \mathrm{~m}$ aos 19 anos, ou seja, um incremento anual médio de crescimento do diâmetro de 3,24 cm/ano e da altura de 1,47 m/ano. No ano de 2003, num universo de 74 castanheiras em floresta primária, a produção total de castanha foi de $247,1 \mathrm{~kg}$ de castanhas (safra muito baixa), que renderia $\mathrm{R} \$ 494,17$ (US\$1 64.72) no caso de o quilo ser comercializado ao preço de $\mathrm{R} \$ 2,00$ (US\$0.67).

Palavras-chave: Bertholletia excelsa. Castanha-do-Brasil. Plantios florestais. Floresta tropical primária. Amazônia.

\footnotetext{
I Museu Paraense Emilio Goeldi. Belém, Pará, Brasil (salomao@museu-goeldi.br) (nelsonrosa@aol.com).

II Mineração Rio do Norte. Assessoria Ambiental. Porto Trombetas, Pará, Brasil (alexandre@mrn.com.br).

III Museu Paraense Emílio Goeldi. Bolsista. Graduando em Engenharia Florestal. Belém, Pará, Brasil (kacio_andrey@yahoo.com.br).

1 Projeto Monitoramento de Florestas Plantadas e Primárias, financiado pela Mineração Rio do Norte. S. A.
}

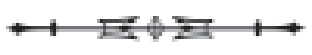


Castanheira-do-brasil recuperando áreas degradadas e provendo alimento e renda...

Abstract: The role of Brasil nut in the restoring degraded Amazonian forest and supplementing local income - Brazil nut trees (Bertholletia excelsa H. \& B. - Lecythidaceae) - are the largest girthed trees in Amazonian forests. Trees can range from 4.34 to $5.25 \mathrm{~cm}$ in $\mathrm{dbh}$ (diameter at breast high). There is evidence that some reproductive Brazil nut trees can be over 1,000 years old. The objectives of study is to examine the growth rate of Brazil nut trees in a multi-species reforestation system of areas degraded by mining activities and estimate the seed yield for local communities in the Sacará-Taqüera National Forest of Pará, Brazil. The study was carried out in an area of 19.4 ha being restored since 1994 with several species including 482 Brazil nut trees. To evaluate seed production, a pilot study will be used to quantify seed production from 2003 to 2007. The average for Brazil nut trees was 24,8 trees/ha. The lowest diameter was $2.1 \mathrm{~cm}$ and the largest was $61.6 \mathrm{~cm}(=19.4 \mathrm{~cm})$. This resulted in a mean increment of 0.11 to $3.24 \mathrm{~cm} /$ year. The variation in height ranged from $3 \mathrm{~m}$ to $28 \mathrm{~m}(=14.7 \mathrm{~m})$ and height increment varied from 0.16 to $1.47 \mathrm{~m} /$ year $(=0.77 \mathrm{~m} /$ year $)$. To estimate fruit production, 84 trees were selected at one site with a high tree density (=14 trees/ha). In 2003, 74 trees produced fruits (= 29 fruits/tree) with a mean of 16 seeds per fruit. The mean production was 477 seeds per tree, which was considered low. Normally, the seed production in this region is 800 hectoliters $(34,000 \mathrm{~kg})$ which is equivalent to US\$22,666.67. The total income derived from the seed harvest per individual is US\$755.67 for a 3 month period or US $\$ 252 /$ month, which was higher than the background average of US $\$ 100.00 /$ month. The plantation of Brazil nut trees in a multi-species restoration system in Eastern Amazon is an excellent opportunity to both forest conservation and local revenues. The selection of highly productive trees can result in trees attaining $60 \mathrm{~cm} d b h$ and $28 \mathrm{~m}$ height in only $19 \mathrm{yrs}$. In the 2003, 74 trees in primary forest produced an average of $247 \mathrm{~kg}$ of seeds which is equivalent to US\$164.72/tree in the local market.

Keywords: Bertholletia excelsa. Brazil-nuts. Plantation nut trees. Rain forest. Amazonia.

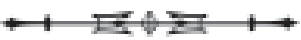




\section{INTRODUÇÃO}

A castanheira-do-brasil, castanheira-do-pará ou simplesmente castanheira (Bertholletia excelsa H. \& B. - Lecythidaceae) é a espécie que apresenta o tronco mais grosso entre todas as espécies da floresta amazônica, ou seja, é a de maior diâmetro; já as mais altas são as espécies do grupo dos angelins, que chegam a mais de $60 \mathrm{~m}$ de altura enquanto que a castanheira chega a $50 \mathrm{~m}$ - o piquiá e a samauma são sempre menores. A castanheira, assim como piquiá, o bacurí, entre outras, é considerada espécie social, pois suprirá frutos e renda para os comunitários locais. Camargo et al. (1994) estimaram uma idade de 440 anos \pm 60 anos para um exemplar com $233 \mathrm{~cm}$ de diâmetro a 1,3 m do solo (DAP). Existem fortes evidências de que alguns exemplares de castanheira possam ser milenares (SALOMÃO, 1991; CAMARGO et al., 1994). Exemplares com 5,25 m e 4,34 m de DAP são apresentados por Salomão (1991). Num outro estudo no Platô Almeidas, na Flona Saracá-Taqüera/ Ibama, em Porto Trombetas, estado do Pará, Salomão et al. (2002a) apresentam 10 castanheiras com diâmetros superiores a $3 \mathrm{~m}$.

A castanheira ocorre em agrupamentos mais ou menos extensos (bolas na linguagem do caboclo) denominados castanhais. Sua área de ocorrência vai desde o extremo sul das Guianas até o Alto Beni $14^{\circ}$ de latitude Sul no sul do Mato Grosso (MÜLLER et al., 1980); seu limite leste encontra-se a noroeste do Maranhão, bacia do rio Gurupi, estando ausente em toda a parte ocidental da hiléia em ocorrência espontânea (DUCKE; BLACK, 1954).

Numa bola de castanha (expressão cabocla) ou castanhal, pode-se encontrar de 1 a 15 castanheiras por hectare (SALOMÃO, 1991; SALOMÃO et al., 2002), sendo a média geral para as áreas de ocorrência na Amazônia de 1,5 árvore/ha. Inúmeros estudos sobre a espécie foram compilados num banco bibliográfico por Pereira e Costa (1981). Moritz (1984) estudou detalhadamente os fatores biológicos da floração e frutificação da castanheira. Cavalcante (1988) comenta sobre diversos aspectos da árvore e do fruto da castanheira. O papel econômico e, sobretudo, social dos castanhais são discutidos e interpretados por Kitamura e Müller (1984), que propõem algumas medidas para a preservação, em detrimento da depredação dos mesmos. Bentes, Marin e Emmi (1988) documentaram a destruição acelerada dos castanhais do Tocantins, apesar da proibição do abate e da comercialização da castanheira desde 1987, através de Portaria do Ibama. Peres et al. (2003) analisaram as ameaças demográficas à sustentabilidade da exploração da castanha em 21 populações espalhadas pela Amazônia brasileira, boliviana e peruana, mostrando que o nível de coleta é o determinante principal da estrutura de tamanho das populações. Informações sobre a estrutura e a fitossociologia de castanheiras são citadas por Pires $(1973,1976)$, Radambrasil (1974, 1976), Campbell et al. (1986), Salomão, Silva e Rosa (1988).

Na Floresta Nacional Saracá-Taqüera, em Porto Trombetas, Pará, a Mineração Rio do Norte (MRN) promove a lavra da bauxita desde 1979. O minério encontra-se no subsolo (entre 4 e $6 \mathrm{~m}$ de profundidade) em área coberta pela floresta ombrófila densa. De acordo com a meta anual de produção, a empresa desmata, atualmente, áreas que variam de 400 a 500 ha por ano. Após a lavra, inicia-se o processo de restauração da paisagem florestal através do reflorestamento com espécies arbóreas quase que exclusivamente nativas da Amazônia e, também, pela adição de solo superficial 'terra-preta' nas áreas de plantio. É oportuno ressaltar que o ecossistema artificial formado após a lavra da bauxita pode ser classificado como o extremo da degradação ambiental, pois as propriedades físicas, químicas e biológicas do solo foram profundamente alteradas, sendo superado somente pelos 'lagos de rejeito' estudados por Franco et al. (1992).

Ao conjunto dos processos utilizados para recompor ecossistemas, tendo em vista as condições iniciais

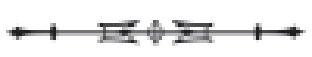


naturais, as alterações registradas e os prognósticos resultantes do monitoramento denominam-se restauração ambiental e para floresta, especificamente, restauração florestal. Restauração é o retorno de uma condição perturbada ou totalmente alterada a um estado anterior existente naturalmente, ou seja, restauração refere-se ao retorno a um estado préexistente sem, necessariamente, que o sistema retorne às suas características originais.

Segundo Carpanezzi et al. (1990), ecossistema degradado é aquele que, após distúrbios, teve eliminado, juntamente com a vegetação, os seus meios de regeneração bióticos, como o banco de sementes, banco de plântulas, chuva de sementes e rebrota. Apresenta, portanto, baixa resiliência, isto é, seu retorno ao estado anterior pode não ocorrer ou ser extremamente lento. Nestes ecossistemas degradados, a ação antrópica para a recuperação é necessária, pois eles já não mais dispõem daqueles eficientes mecanismos de regeneração.

paradigma da reabilitação da paisagem florestal deve aliar o reflorestamento à melhoria das condições que propiciam a sucessão natural no menor espaço de tempo possível e ao menor custo. Isso propiciaria o máximo de acumulação de biomassa aliada a uma alta biodiversidade, de tal forma que os benefícios sociais e ecológicos da recuperação de áreas degradadas, em regiões originalmente cobertas por florestas, sejam otimizados pela instalação de sistemas agroflorestais (WANDELLI et al., 1997) ou pela conservação ambiental em si (CARPANEZZI et al., 1990).

A recuperação de um ambiente natural, diferentemente da recomposição, que é a restauração natural do ambiente sem a interferência do homem, necessita de técnicas silviculturais e de manejo florestal para lograr êxito. Nos processos de recuperação podem ser usadas duas técnicas distintas: restauração e reabilitação.

Segundo Viana (1990), a restauração refere-se ao conjunto de tratamentos que visam a recuperar a forma original do ecossistema, ou seja, a sua estrutura original, a dinâmica e as respectivas interações biológicas. Ela é geralmente recomendada para ecossistemas raros e ameaçados, demandando maior tempo e resultando em custos significativamente maiores.

A reabilitação diz respeito a tratamentos que buscam a recuperação de uma ou mais funções do ecossistema, que podem ser basicamente econômica ou ambiental (JESUS, 1997). Ela é aplicada, geralmente, em áreas onde o nível de degradação é elevado (como nas áreas de mineração) e há a necessidade de imediata recuperação.

Os plantios de enriquecimento e o manejo da regeneração natural têm sido as práticas mais recomendadas para a recuperação de fragmentos degradados e podem, ainda, ser utilizadas em áreas muito degradadas e que não conservam nenhuma das caracterísiticas bióticas da formação original (RODRIGUES; GANDOLFI, 1996).

Este trabalho objetivou analisar como se comporta a castanheira, em termos de crescimento do diâmetro e da altura, em plantios que visam à restauração da paisagem florestal em áreas degradadas pela mineração a céu aberto, assim como avaliar a produção de um castanhal em um fragmento de floresta primária no que se refere à safra e renda de uma comunidade de castanheiros na região de Porto Trombetas.

\section{MATERIAL E MÉTODOS}

\section{Área de estudo}

A área de estudo encontra-se inserida na Floresta Nacional Saracá-Taqüera, sob gestão do Ibama, onde está instalado o projeto de mineração de bauxita da Mineração Rio Norte (MRN) (1 ${ }^{\circ} 40^{\prime} \mathrm{S}-56^{\circ} 27^{\prime} \mathrm{W}$, atitude de $180 \mathrm{~m}$ ), implantado na década de 1970, no distrito de Porto Trombetas, município de Oriximiná, estado do Pará.

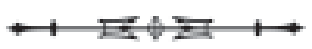


A Flona está localizada na sub-região dos baixos platôs da Amazônia, domínio da floresta densa das baixas altitudes, cuja fisionomia apresenta dois estratos distintos: um emergente e outro uniforme. Trata-se de uma floresta que se destaca no bioma amazônico por apresentar altos valores de diversidade arbórea e biomassa e, também, elevado volume de madeira de grande valor comercial.

O clima da região é o AF1, que apresenta precipitação pluviométrica média anual variante entre $2.500 \mathrm{~mm}$ e 3.000 mm. Como regra geral na Amazônia, o clima apresenta dois períodos climáticos distintos: inverno, de janeiro a maio, quando ocorrem as maiores precipitações pluviométricas; e verão, de julho a dezembro, quando a estiagem é acentuada. A temperatura média, a precipitação pluviométrica, a umidade relativa e a insolação anual para região são, respectivamente, $26^{\circ} \mathrm{C}, 2.197 \mathrm{~mm}, 81 \% \mathrm{e}$ $2.026 \mathrm{~h}$.

Na bacia amazônica os depósitos de bauxita são associados à série Barreiras do Terciário, constituídos de arenitos, siltitos e, ocasionalmente, conglomerados. As lateritas são encontradas no topo dos platôs, fortemente dissecados pela erosão, remanescentes do peneplano Terciário, que se estendem ao longo do lado nordeste do rio Amazonas, desde as vizinhanças de Oriximiná até Jardiândia, no rio Jari (LAPA, 2000). Estes platôs são bem definidos, têm os topos e planos achatados, cuja elevação varia de 70 a 120 m, com altitude de 150 a 200 m em relação ao nível do mar.

Geomorfologicamente, a região encontra-se na unidade morfoestrutural do Planalto Dissecado rio Trombetas - rio Negro. Nas proximidades da margem direita do rio Trombetas há relevos tabulares onde ocorre a exploração de bauxita (RADAMBRASIL, 1976). Predominam na área o latossolo amarelo distrófico, textura muito argilosa, e o latossolo amarelo distrófico, textura argilosa, sob floresta densa de relevo plano com bordos dissecados (RADAMBRASIL, 1976).
A área acha-se inserida na região da Floresta Tropical Densa, sub-região dos Baixos Platôs da Amazônia, domínio da floresta densa das baixas altitudes, cuja fisionomia refere-se à floresta localizada, principalmente, nos platôs Terciários e terraços antigos e recentes, apresentando-se em dois estratos distintos: um emergente e outro uniforme (RADAMBRASIL, 1976). As principais espécies que caracterizam o estrato emergente são: Dinizia excelsa (angelim-pedra), Bertholletia excelsa (castanheira) e Cedrelinga catanaeformis (cedrorana). estrato uniforme é caracterizado por Manilkara spp (maçarandubas), Protium spp (breus) e Pouteria spp (abius). Tratam-se de florestas com alto volume de madeira de grande valor comercial. Comparada com outras áreas florestais da Amazônia é uma das mais belas, com sub-bosque limpo, boa regeneração natural e fácil penetração (RADAMBRASIL, 1976).

A área específica de estudo do papel da castanheira na restauração da paisagem florestal refere-se àquelas áreas de mineração a céu aberto que se encontram no extremo da degradação ambiental quando comparadas com aquelas oriundas do deficiente manejo para agricultura e pecuária no nordeste do Pará - a mais antiga área de colonização agrícola da Amazônia brasileira (VIEIRA et al., 1996).

Sintetizando a descrição da paisagem predominante, tem-se que, para a lavra do minério, é necessária a remoção da vegetação (no caso de Porto Trombetas trata-se da floresta ombrófila) e a retirada de uma camada de solo que varia de 4 a $6 \mathrm{~m}$ a fim de chegar ao minério (bauxita). Após a lavra, a terra retorna ao buraco da cava sendo espalhada por um trator de esteira. Na finalização do preparo do solo é incorporada a terra-preta (serrapilheira + horizonte A), formando uma camada de 10 a $20 \mathrm{~cm}$. A seguir, inicia-se o processo de recomposição da paisagem florestal através dos reflorestamentos, com o emprego de várias espécies, entre elas, a castanheira, piquiá, bacuri e uxi, consideradas 'espécies sociais', pois suprirão frutos e renda para os comunitários locais, e da facilitação da regeneração natural através

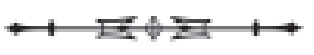


do banco de sementes que se encontra na 'terrapreta' (SALOMÃO et al., 1997). Na avaliação desse processo, fica evidenciado que todas as propriedades químicas, físicas, biológicas e ecológicas do solo foram drástica e extremamente alteradas, daí concluise que as áreas de mineração encontram-se no extremo da degradação ambiental.

O estudo da avaliação da safra de castanha foi realizado em uma das quatro reservas fragmentadas de castanheiras do Platô Almeida. A delimitação dessas reservas atende a uma das condicionantes do Ibama para o licenciamento de lavra naquele local. A reserva escolhida situa-se a leste por propiciar maior número de indivíduos por unidade de área.

\section{Avaliação do crescimento em diâmetro e altura em área degradada}

A avaliação do crescimento em diâmetro e altura de castanheiras em reflorestamentos heterogêneos teve por base o plantio florestal efetuado pela MRN, em 1984, quando foram empregadas 67 espécies arbóreas.

Num bloco de 19,4 ha procedeu-se o levantamento de todas as castanheiras presentes na época (fevereiro de 2003). A área foi dividida em faixas de $20 \mathrm{~m}$ de largura com comprimento variável, na direção norte-sul. Cada faixa foi subdividida em quadras de $25 \mathrm{~m}\left(500 \mathrm{~m}^{2}\right)$ e balizadas com tubos de pvc (1 m de comprimento por $1 / 2$ de diâmetro) pintados na cor laranja.

Todos os indivíduos, independentemente do diâmetro, foram registrados recebendo uma placa de alumínio cuja numeração acusava a quadra de ocorrência e o respectivo número da árvore, como, Q-10-Árv 67. As placas foram fixadas nos troncos com arame inoxidável. Foi medido o DAP (diâmetro a 1,3 $\mathrm{m}$ do solo) e estimadas as alturas do fuste e da copa através de uma vara de $5 \mathrm{~m}$ dividida a cada metro (essas alturas eram fornecidas sempre pelo mesmo auxiliar). A fenofase de cada indivíduo foi também anotada. Todos os indivíduos registrados foram monitorados a intervalos de dois anos para acompanhamento do crescimento.

\section{Avaliação da safra de castanha em floresta primária}

Para avaliação da safra anual de castanheiras em floresta primária foi implantado, em 2003, um estudo para monitorar a safra anual, por um período de cinco anos (2003 a 2007), na Reserva Leste de Castanheira (6 ha), no Platô Almeidas. Foram registradas e plaqueadas todas as árvores com DAP3 $10 \mathrm{~cm}$ e também medidos o DAP e as alturas do fuste e copa.

Considerando que a safra regional é de janeiro a maio, com pico em março, foram feitas contagens e pesagens de ouriços e castanhas (amêndoas) nos meses de fevereiro, abril e junho. Na área de projeção da copa, foram contados todos os ouriços e marcados com tinta spray nas cores vermelha, amarela e azul, respectivamente, para aqueles meses de monitoramento.

Para cada 15 ouriços de uma mesma árvore, coletava-se um para pesagem (tanto do ouriço quanto das castanhas) e contagem do número de castanhas em cada ouriço. Quando uma castanheira apresentava menos de 15 e mais de sete ouriços, coletava-se um para amostragem, ou seja, quando havia de 1 a sete ouriços descartava-se da amostragem e de 8 a 15 considerava-se.

\section{RESULTADOS E DISCUSSÃO}

\section{Crescimento em diâmetro em área degradada}

$\mathrm{Na}$ área de 19,4 ha do reflorestamento de 1984, foram registradas 482 castanheiras vivas, aos 19 anos de idade (considerando-se um ano no viveiro para germinação e produção da muda), acarretando uma abundância de 24,8 árvores/ha.

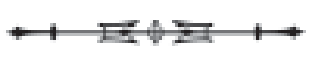


menor diâmetro mensurado foi de $2,1 \mathrm{~cm}$, o maior de 61,6 cm (Figura 1) e o diâmetro médio foi de 19,4 cm. Nove indivíduos apresentaram diâmetro inferior a $5 \mathrm{~cm}$, enquanto, no outro extremo, três árvores apresentaram DAP superior a $50 \mathrm{~cm}$. Abaixo de $20 \mathrm{~cm}$ observou-se 362 árvores (75,1\%); entre $20 \mathrm{~cm}$ e $40 \mathrm{~cm}$ outras 110 (22,8\%); e acima de 40 apenas 10 árvores (ou 2,1\%); a maioria (282 indivíduos), equivalente a 58,5\%, apresentou diâmetro inferior a $15 \mathrm{~cm}$ (Figura 2).

O incremento médio anual do crescimento diamétrico apresentou uma amplitude muito grande, variando de $0,11 \mathrm{~cm} /$ ano (DAP de $2,1 \mathrm{~cm}$ ) até 3,24 cm/ano (DAP de 61,6 cm) - média de $1,02 \mathrm{~cm} / a n o$, equivalente a um DAP médio de $19,4 \mathrm{~cm}$. No extremo inferior (DAP $\notin 5 \mathrm{~cm}$ ) obteve-se cinco exemplares com incremento médio de $0,26 \mathrm{~cm} / a n o$, enquanto que no extremo superior (DAP $360 \mathrm{~cm}$ ) há um incremento de 3,24 cm/ano.

Existem 120 árvores (24,9\% do total) com diâmetros superiores a $20 \mathrm{~cm}$ e incremento anual superior a $1 \mathrm{~cm} / a n o$. Duas castanheiras apresentaram incremento diamétrico anual superior a $3 \mathrm{~cm} / \mathrm{ano}$ (3,24 cm/ano e 3,03 cm/ano); oito apresentaram incrementos entre $3 \mathrm{~cm} / \mathrm{ano}$ e $2 \mathrm{~cm} / \mathrm{ano} ; 190$ (ou $38,4 \%$ ) apresentaram incremento entre $2 \mathrm{~cm} / \mathrm{ano}$ e 0,9 cm/ano, enquanto a maioria, 282 (58,5\%), apresentaram incrementos entre $0,1 \mathrm{~cm} / \mathrm{ano}$ e $0,7 \mathrm{~cm} / a n o$. Percebe-se que praticamente $42 \%$ das castanheiras têm incremento diamétrico médio anual superior a 0,9 cm/ano. Caso sejam escolhidas boas matrizes, pode-se facilmente obter espécies com
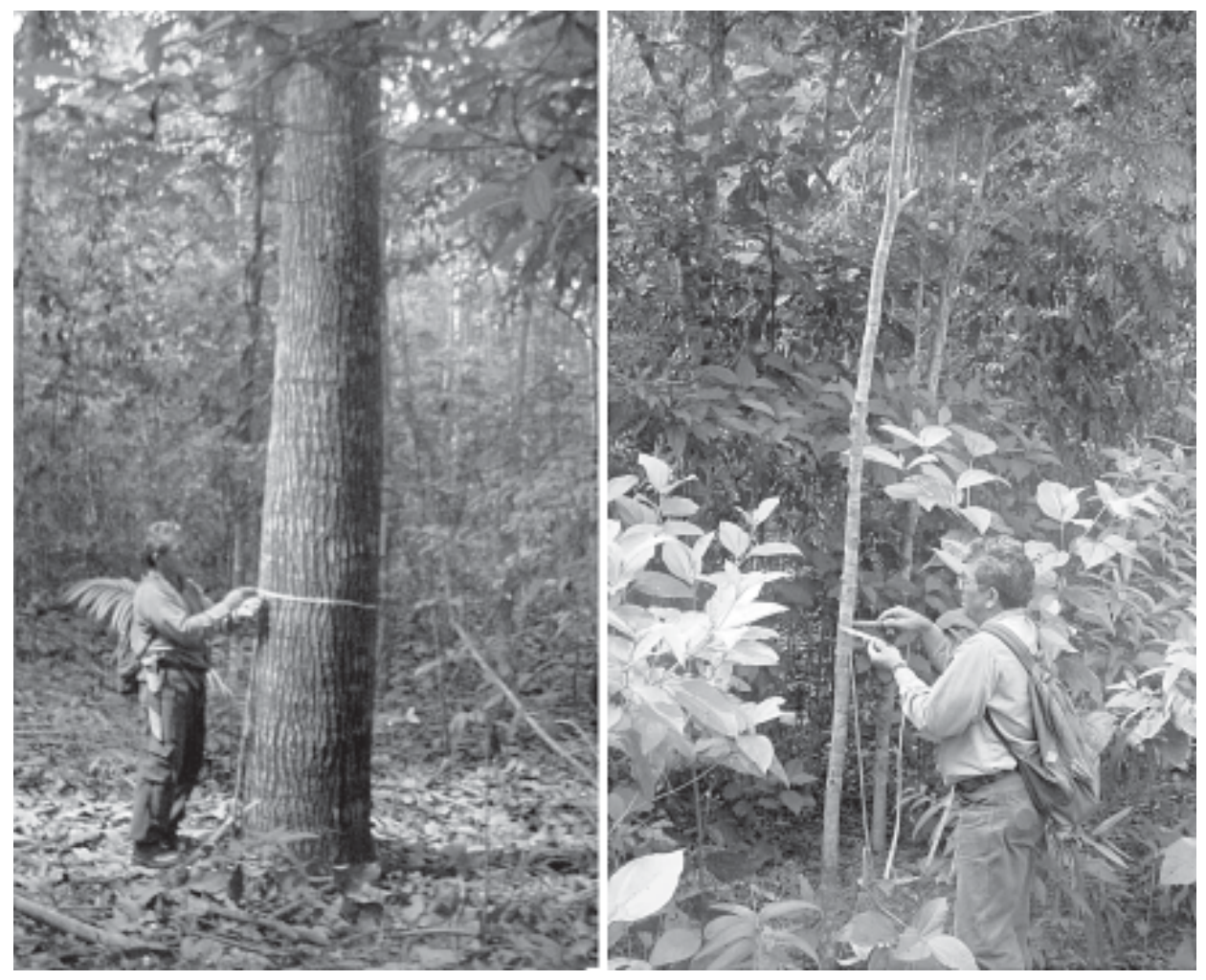

Figura 1. Maior castanheira em diâmetro (DAP = 61,6 cm) registrada em 19,4 ha no reflorestamento de 1984 da MRN (esquerda) e menor exemplar (DAP = 2,1 cm), também no referido plantio (direita), Porto Trombetas, Oriximiná, Pará. Fotos: R.P. Salomão, 2003.

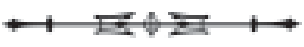


incrementos superiores a $2 \mathrm{~cm} / \mathrm{ano}$, o que qualifica a castanheira como uma excelente espécie para recuperação de áreas degradadas.

Como se comportam esses incrementos face aos de outras espécies utilizadas na recuperação de áreas degradadas em Porto Trombetas e, também, em relação a outros locais da Amazônia?

Para responder o primeiro item, analisaram-se os resultados relativos aos quatro primeiros anos do monitoramento dos reflorestamentos anuais plantados entre 1981 a 1996, pela MRN, em Porto Trombetas. Salomão e Rosa (2000) e Salomão, Matos e Rosa (2002) avaliaram o crescimento anual do diâmetro basal médio de 34 espécies que apresentaram 20 ou mais indivíduos ( ${ }^{3}$ 20) no referido período de monitoramento. Para cada espécie foi calculado o incremento periódico anual (IPA), entre 1996 e 1999, relativo ao crescimento anual do diâmetro basal de cada indivíduo, gerando-se, a seguir, o IPA médio da espécie (IPA MÉn SP $_{\text {SP }}$ ).
Procedeu-se a análise de variância desta variável e aplicou-se o teste de Tuckey (95\% de probabilidade) para identificar aquelas espécies com IPA semelhantes. Quatro espécies foram consideradas como excelentes quanto à aptidão ecológica por apresentarem incremento anual superior ao dobro da média geral; seis espécies foram classificadas como boas (incremento entre a média e o dobro dela); exatos 50\% das espécies analisadas foram consideradas com aptidão regular (incremento entre a média e a metade dela); e sete espécies foram enquadradas como de fraca aptidão, com incremento inferior a metade da média (Tabela 1).

Considerando-se o incremento diamétrico médio calculado para as 482 castanheiras do reflorestamento de 1984 (1,02 cm/ano), observa-se que esta espécie seria considerada como de boa aptidão. Caso se trabalhe com clones daqueles indivíduos de maior incremento (superior a 3,0 cm/ano), ter-se-ão indivíduos de castanheira

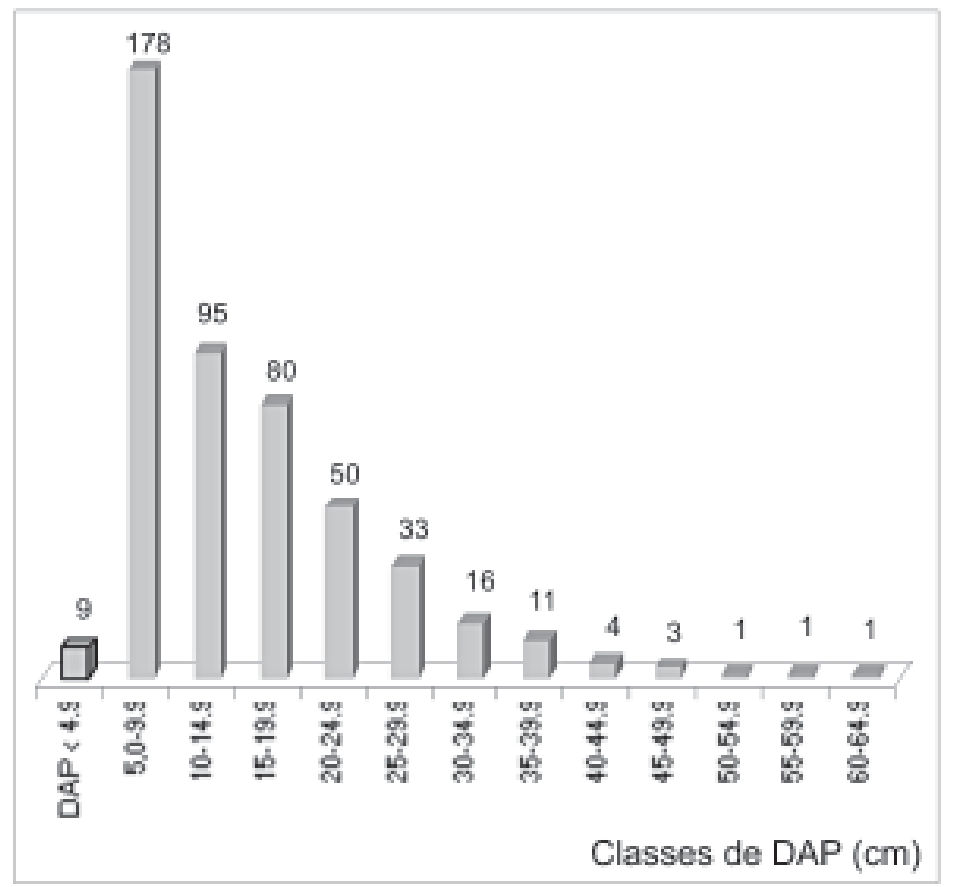

Figura 2. Distribuição em classes diamétricas das 482 castanheiras, em 19,4 ha do reflorestamento de 1984, monitoradas na Flona Saracá-Taqüera/Ibama, Porto Trombetas, Oriximiná, Pará.

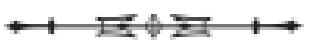


Bol. Mus. Para. Emilio Goeldi. Ciências Naturais, Belém, v. 1, n. 2, p. 65-78, maio-ago. 2006

Tabela 1. Classificação das espécies arbóreas de acordo com o índice da espécie para incremento periódico anual do crescimento diamétrico (IPA Méno sp ), segundo o teste de Tuckey (95\% de probabilidade), Porto Trombetas, Oriximiná, Pará. Tabela extraída de Salomão et al. $\left(2000_{\mathrm{b}}\right)$. Médias ligadas com uma mesma letra não são significativamente diferentes (G.L =1950, QME $=0.4374$, ALFA $=$ $0.05) ; 2$ ÍNDICE $_{S P}=\mathrm{IPA}_{\text {MÉDIO SP }} *\left[\left(\mathrm{~S}^{\mathrm{n}=1} \AA^{34} \mathrm{IPA}_{\text {MÉDIO } S P}\right) / \mathrm{N}^{\circ} S P P\right]^{-1}$.

\begin{tabular}{|c|c|c|c|c|c|c|c|c|c|c|}
\hline ESPÉCIE & NOME POPULAR & $N^{\circ} \operatorname{IND}(n)$ & $\begin{array}{l}\text { IPA }_{\text {MÉDIO }} \\
\left(\mathrm{cm}^{*} \mathrm{anO}^{-1}\right)\end{array}$ & \multicolumn{6}{|c|}{ GRUPO । } & ÍNDICE $_{\text {Sp }}{ }^{2}$ \\
\hline Senna multijuga & mari-mari pequeno & 52 & 3,22 & a & & & & & & 3,29 \\
\hline Stryphnodendron guianensis & fava camuzê & 23 & 2,85 & a & $b$ & & & & & 2,91 \\
\hline Sclerolobium paniculata & tachí-do-campo & 25 & 2,43 & & $b$ & c & & & & 2,48 \\
\hline Tapirira guianensis & tatapiririca & 114 & 2,13 & $d$ & & c & & & & 2,18 \\
\hline Acacia polyphylla & paricá-de-espinho & 89 & 1,78 & d & e & & & & & 1,82 \\
\hline Anacardium occidentale & caju & 36 & 1,58 & & e & $f$ & & & & 1,62 \\
\hline Parkia multijuga & paricá grande & 147 & 1,44 & $g$ & $\mathrm{e}$ & $f$ & & & & 1,47 \\
\hline Inga edulis & ingá cipó & 23 & 1,38 & $g$ & $\mathrm{e}$ & $f$ & h & & & 1,41 \\
\hline Eugenia cumini & azeitona & 30 & 1,08 & $g$ & & $f$ & h & i & & 1,10 \\
\hline Abarema turbinata & fava-olho-de-peixe & 64 & 1,01 & $g$ & j & & h & $\mathrm{i}$ & & 1,03 \\
\hline Guatteria olivacea & envira preta & 28 & 0,88 & & j & k & $\mathrm{h}$ & i & & 0,90 \\
\hline Bowdichia nitida & sucupira escamosa & 47 & 0,87 & & j & k & $\mathrm{h}$ & $\mathrm{i}$ & & 0,89 \\
\hline Enterolobium schomburgkii & fava-de-rosca & 111 & 0,85 & & j & k & h & i & & 0,87 \\
\hline Caesalpinia ferrea & jucá & 57 & 0,84 & & j & k & $\mathrm{h}$ & $\mathrm{i}$ & & 0,86 \\
\hline Leucaena leucocephala & leucena & 87 & 0,82 & & j & k & & i & & 0,84 \\
\hline Licania tomentosa & oiti & 27 & 0,80 & 1 & j & k & & $\mathrm{i}$ & & 0,82 \\
\hline Lophanthera lactescens & lanterneira & 81 & 0,80 & 1 & j & k & & $\mathrm{i}$ & & 0,82 \\
\hline Dalbergia spruceana & jacarandá-do-pará & 95 & 0,79 & 1 & j & k & & i & & 0,81 \\
\hline Tabebuia serratifolia & pau d'arco amarelo & 32 & 0,79 & 1 & j & k & & $\mathrm{i}$ & & 0,81 \\
\hline Hymenaea courbaril & jatobá & 54 & 0,77 & 1 & j & k & $\mathrm{m}$ & $\mathrm{i}$ & & 0,79 \\
\hline Guatteria umbonata & envira preta & 27 & 0,75 & 1 & j & k & $\mathrm{m}$ & i & & 0,77 \\
\hline Tachigalia alba & tachi preto & 26 & 0,69 & 1 & j & k & $\mathrm{m}$ & $\mathrm{i}$ & $n$ & 0,71 \\
\hline Aspidosperma macrocarpum & piquiá marfim & 21 & 0,68 & 1 & j & k & $\mathrm{m}$ & $\mathrm{i}$ & $n$ & 0,70 \\
\hline Geissospermum serriceum & quinarana & 99 & 0,61 & 1 & j & k & $\mathrm{m}$ & $\mathrm{i}$ & $n$ & 0,62 \\
\hline Genipa americana & jenipapo & 100 & 0,52 & 1 & j & k & $\mathrm{m}$ & & $\mathrm{n}$ & 0,53 \\
\hline Micropholis venulosa & abiu rosadinho & 28 & 0,47 & 1 & j & k & $\mathrm{m}$ & & $n$ & 0,48 \\
\hline Astronium gracile & muiracatiara & 98 & 0,46 & 1 & j & k & $\mathrm{m}$ & & $n$ & 0,47 \\
\hline Mezilaurus itauba & itaúba-preta & 94 & 0,41 & 1 & & k & $\mathrm{m}$ & & $\mathrm{n}$ & 0,42 \\
\hline Dipteryx odorata & cumarú & 83 & 0,40 & 1 & & k & $\mathrm{m}$ & & $\mathrm{n}$ & 0,41 \\
\hline Swartzia brachyrachys & pacapeuá & 27 & 0,37 & 1 & & k & $\mathrm{m}$ & & $n$ & 0,38 \\
\hline Spondias lutea & taperebá & 44 & 0,27 & 1 & & & $\mathrm{~m}$ & & $n$ & 0,28 \\
\hline Pouteria speciosa & pajurá-de-óbidos & 46 & 0,26 & l & & & $\mathrm{m}$ & & $n$ & 0,27 \\
\hline Platimyscium duckei & macacaúba & 31 & 0,23 & & & & $\mathrm{~m}$ & & $\mathrm{n}$ & 0,24 \\
\hline Clarisia racemosa & guariúba & 39 & 0,16 & & & & & & $n$ & 0,16 \\
\hline
\end{tabular}

com excelente performance na restauração da paisagem florestal em áreas degradadas. Deve-se ressaltar, ainda, que os incrementos apresentados pelas espécies da Tabela 1 foram calculados em função do diâmetro basal das mudas (diâmetro ao nível do solo) e não em função do DAP, como nas castanheiras.
Com relação ao segundo item do questionamento, sobre como estariam situados estes incrementos do crescimento diamétrico em áreas degradadas em relação a outros locais antropizados da Amazônia (excetuando-se as áreas degradadas), analisaram-se os resultados de Leão, Ohashi e Vieira (2004) que retratam, entre outros, o crescimento em diâmetro 
e altura de 29 espécies plantadas em 22,63 ha do banco de germoplasma ex situ da Hidrelétrica de Tucuruí, denominado Ilha de Germoplasma, no município de Tucuruí, Pará. Os resultados referem-se ao período de crescimento desde o plantio (1985) até o ano de 2000, correspondente a 15 anos (Tabela 2). A itha de Germoplasma, com 129 ha, é um empreendimento ambiental mantido pela Eletronorte há 20 anos que abriga, também, um banco de germoplasma in situ que possibilita a conservação de material genético de espécies florestais submersas com a formação do lago da hidrelétrica.
Os maiores crescimentos diamétricos observados foram de 48,8 cm e $42 \mathrm{~cm}$ em exemplares de parapará (J. copaia) e virola ( $V$. surinamensis), respectivamente, enquanto os menores foram de $6,7 \mathrm{~cm}$ e $6,4 \mathrm{~cm}$ em indivíduos de cupuaçu ( $T$. grandiflorum) e bacuri-pari ( $R$. gardneriana), respectivamente. Todas as demais 27 espécies apresentaram DAP máximo inferior a $40 \mathrm{~cm}$ durante os 15 anos analisados.

O diâmetro médio das espécies variou de $27 \mathrm{~cm}$ para o taperebá a $4,5 \mathrm{~cm}$ para o cupuaçu e o acapu

Tabela 2. Crescimento em diâmetro e altura total, no período de 15 anos (1985 a 2000), de 29 espécies arbóreas amazônicas do banco de germolasma ex situ da Hidrelétrica de Tucuruí, município de Tucuruí, Pará. Adaptado de Leão, Ohashi e Vieira (2004). Convenções: Mín = mínimo, Máx = máximo, Méd = médio, IMA = incremento médio anual, $\mathrm{H}=$ altura total.

\begin{tabular}{|c|c|c|c|c|c|c|c|c|c|}
\hline ESPÉCIE & NOME POPULAR & 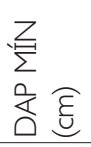 & 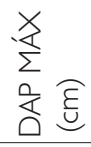 & 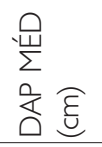 & 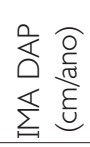 & 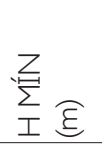 & $\sum_{I}^{X}$ & $\stackrel{\ominus}{\sum_{I}} \widehat{E}$ & 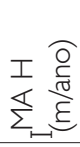 \\
\hline Euterpe oleracea & açaí & 3,5 & 9,6 & 6,8 & 0,45 & 2,3 & 7,5 & 6,2 & 0,41 \\
\hline Vouacapoua americana & acapu (pleno sol) & - & - & 9,5 & 0,63 & - & - & 9,5 & 0,63 \\
\hline Vouacapoua americana & acapu (sombra) & - & - & 4,5 & 0,30 & - & - & 6,5 & 0,43 \\
\hline Apuleia leiocarpa & amarelão & 13,8 & 25,9 & 18,0 & 1,20 & 11,1 & 23,1 & 17,0 & 1,13 \\
\hline Carapa guianensis & andiroba & 1,5 & 11,9 & 7,4 & 0,49 & 4,7 & 11,2 & 8,1 & 0,54 \\
\hline Dinizia excelsa & angelim pedra & 11,2 & 26,5 & 19,9 & 1,33 & 9,5 & 23,6 & 16,8 & 1,12 \\
\hline Attalea speciosa & babaçu & 0,0 & & & 0,00 & 0,5 & 16,7 & 7,5 & 0,50 \\
\hline Oenocarpus bacaba & bacaba & 18,6 & 29,4 & 23,1 & 1,54 & 7,1 & 14,5 & 11,8 & 0,79 \\
\hline Platonia insignis & bacuri & 4,5 & 17,1 & 12,1 & 0,81 & 5,2 & 16,4 & 10,2 & 0,68 \\
\hline Rheedia gardneriana & bacuri pari & 2,8 & 6,4 & 5,0 & 0,33 & 2,6 & 5,9 & 4,5 & 0,30 \\
\hline Theobroma cacao & cacau & 4,5 & 7,8 & 6,3 & 0,42 & 3,3 & 9,1 & 6,1 & 0,41 \\
\hline Anacardium giganteum & cajuaçu & 9,4 & 20,7 & 16,0 & 1,07 & 6,8 & 18,3 & 12,7 & 0,85 \\
\hline Copaifera martii & copaíba & 4,8 & 12,5 & 14,3 & 0,96 & 13,3 & 17,0 & 13,6 & 0,91 \\
\hline Copaifera reticulata & copaíba & 9,6 & 21,3 & 15,6 & 1,04 & 7,9 & 12,0 & 11,9 & 0,79 \\
\hline Dipteryx odorata & cumaru & 4,8 & 21,2 & 13,2 & 0,88 & 8,4 & 19,5 & 14,3 & 0,96 \\
\hline Theobroma grandiflorum & cupuaçu & 1,2 & 6,7 & 4,5 & 0,30 & 2,3 & 6,9 & 4,0 & 0,27 \\
\hline Stryphnodendron barbadetiman & fava de paca & 21,0 & 27,0 & 23,4 & 1,56 & 14,8 & 17,0 & 16,5 & 1,10 \\
\hline Enterolobium maximum & fava tamboril & 7,9 & 36,8 & 13,2 & 0,88 & 8,3 & 24,9 & 16,8 & 1,12 \\
\hline Hymenaea courbaril var. stilbocarpa & jatobá & 4,5 & 13,7 & 9,0 & 0,60 & 4,6 & 13,2 & 9,9 & 0,66 \\
\hline Dialium guianense & jutaí café & 4,3 & 20,7 & 11,2 & 0,74 & 3,2 & 15,4 & 10,6 & 0,71 \\
\hline Acromia aculeata & macaúba & 29,9 & 39,9 & 32,4 & 2,16 & 14,4 & 17,0 & 14,7 & 0,98 \\
\hline Schefflera morotottonii & morototó & 14,9 & 30,7 & 23,5 & 1,57 & 11,6 & 27,3 & 20,2 & 1,35 \\
\hline Byrsonima aff. laevigata & muruci galego & 5,0 & 15,0 & 9,8 & 0,65 & 4,0 & 10,0 & 6,3 & 0,42 \\
\hline Enterolobium schomburgkii & orelha de negro & 1,3 & 22,7 & 11,9 & 0,79 & 6,3 & 19,9 & 12,9 & 0,86 \\
\hline Jacaranda copaia & parapará & 7,8 & 48,8 & 21,3 & 1,42 & 16,4 & 30,5 & 22,7 & 1,51 \\
\hline Pseudima frutescens & sabonete & 1,2 & 9,0 & 6,8 & 0,46 & 3,4 & 10,1 & 6,9 & 0,46 \\
\hline Lecythis pisonis & sapucaia & 9,5 & 17,2 & 13,7 & 0,91 & 12,7 & 17,7 & 13,6 & 0,90 \\
\hline Spondias mombin & taperebá & 15,9 & 36,2 & 27,0 & 1,80 & 8,5 & 18,0 & 14,6 & 0,97 \\
\hline Virola surinamensis & virola & 4,6 & 42,0 & 19,8 & 1,32 & 5,0 & 26,6 & 15,8 & 1,05 \\
\hline
\end{tabular}

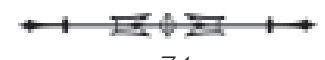


(V. americana) plantado na sombra. Considerando-se o diâmetro médio da castanheira $(19,4 \mathrm{~cm}$ aos 19 anos), observa-se que apenas seis espécies arbóreas apresentam valores superiores a ela: taperebá $(27 \mathrm{~cm})$, morototó - S. morotottonii $(23,5 \mathrm{~cm})$, fava de paca - S. barbadetiman $(23,4 \mathrm{~cm})$, parapará $(21,3 \mathrm{~cm})$, angelim pedra $-D$. excelsa $(19,9 \mathrm{~cm})$ e virola $(19,8 \mathrm{~cm})$ (Tabela 2).

O maior incremento médio anual do crescimento diamétrico (2,16 cm/ano) foi da palmeira macaúba ( $A$. aculeata); entre as árvores o maior foi do taperebá - S. mombin (1,80 cm/ano) e o menor foi do cupuaçu - T. grandiflorum $(0,3 \mathrm{~cm} / \mathrm{ano})$. Nove espécies arbóreas apresentaram incrementos superiores ao da castanheira (1,02 cm/ano), são elas: taperebá (1,80 cm/ano), morototó $(1,57 \mathrm{~cm} / \mathrm{ano})$, fava de paca $(1,56 \mathrm{~cm} / \mathrm{ano})$, parapará $(1,42 \mathrm{~cm} / \mathrm{ano})$, angelim pedra (1,33 cm/ano), virola (1,32 cm/ano), amarelão - A. leiocarpa (1,2 cm/ano), cajuaçu A. giganteum (1,07 cm/ano) e copaíba - C. reticulata (1,04cm/ano); entre as palmeiras, além da macaúba, a bacaba $(O$. bacaba) também apresentou incremento superior, de 1,54 cm/ano (Tabela 2).

Contrastando estes valores (áreas não degradadas) com àqueles observados pelas castanheiras de 19 anos plantadas em áreas degradadas (DAP máximo de $61,6 \mathrm{~cm}$, DAP médio de 19,4cm e incremento médio anual do crescimento diamétrico de 1,02 cm/ano), fica evidenciada a boa adaptação da castanheira em áreas degradadas.

\section{Crescimento em altura em área degradada}

A altura média das árvores de castanheira foi de $14,7 \mathrm{~m}$; a menor altura total foi de $3 \mathrm{~m}$ e a maior de $28 \mathrm{~m}$. Esses valores geraram um incremento médio do crescimento em altura de 0,77 m/ano mínimo de 0,16 m/ano e máximo de 1,47 m. Esses valores referem-se a 365 indivíduos e não ao total registrado de 482 árvores. Quatro indivíduos apresentaram altura total inferior a $5 \mathrm{~m}$, enquanto outras 11 apresentaram altura superior a $25 \mathrm{~m}$. A classe modal para a altura total foi a de 15 a 19,9 m e para a altura do fuste, de 10 a 14,9 cm (Figura 3).

Em Tucuruí, a altura máxima variou de 5,9 m (bacuri pari) a 30,5 m (parapará), enquanto a altura média variou de 4 m (cupuaçu) a 30,5 m (parapará). Com altura média superior a das castanheiras do reflorestamento de 1984 (14,7 m), tem-se parapará (22,7 m), morototó (20,2 m) - ambas madeira mole - amarelão $(17,0 \mathrm{~m})$, fava tamboril E. maximum e angelim pedra (16,8 $\mathrm{m})$, fava de paca (16,5 m) e virola (15,8 m) (Tabela 2).

Com incremento médio anual do crescimento em altura total superior a $0,77 \mathrm{~m}$, apresentado pelas castanheiras do reflorestamento de 1984, há 15 espécies florestais no banco de germoplasma de Tucuruí: parapará (1,51 m/ano), morototó (1,35 m/ano), amarelão (1,13 m/ano), fava tamboril (1,12 m/ano), angelim pedra (1,12 m/ano), fava de paca $(1,10 \mathrm{~m} / \mathrm{ano})$, virola (1,05 m/ano), macaúba $(0,98 \mathrm{~m} / \mathrm{ano})$, bacuri pari $(0,30 \mathrm{~m} / \mathrm{ano})$, cupuaçu $(0,27 \mathrm{~m} / \mathrm{ano})$, taperebá $(0,97 \mathrm{~m} / \mathrm{ano})$, cumaru D. odorata $(0,96 \mathrm{~m} / \mathrm{ano})$, copaíba $(0,91 \mathrm{~m} / \mathrm{ano})$, sapucaia - L. pisonis $(0,90 \mathrm{~m} / \mathrm{ano})$, orelha de negro - E. schomburgkii (0,86 m/ano), cajuaçu (0,85 m/ano),

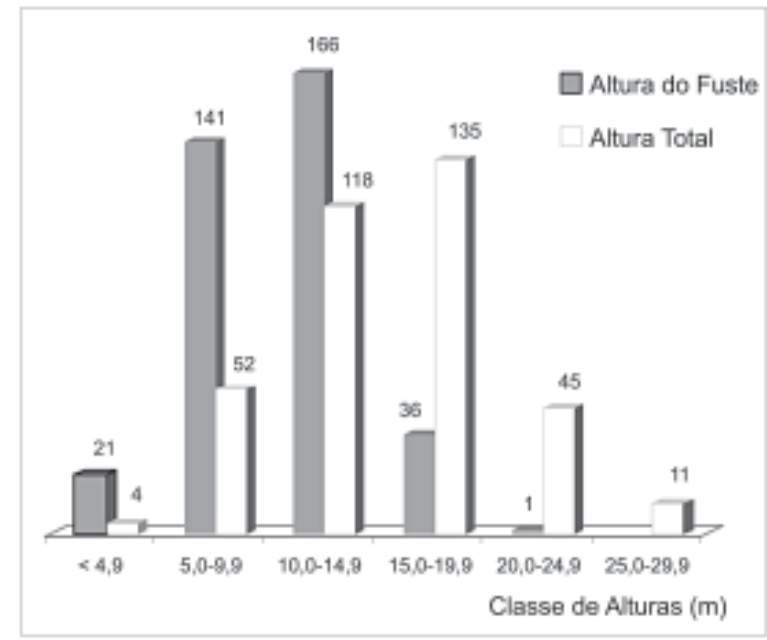

Figura 3. Distribuição em classes de alturas das castanheiras monitoradas na Flona Saracá-Taqüera/Ibama, Porto Trombetas, Oriximiná, Pará.

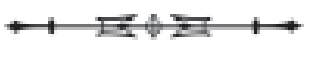


copaíba - C. reticulata e bacaba (ambos com 0,79 m/ano) (Tabela 2). Todavia, todas essas espécies têm incrementos inferiores àqueles apresentados pelas melhores castanheiras do reflorestamento de 1984, que foram próximos de 1,5 m/ano.

\section{Avaliação da safra de castanha em floresta primária}

No estudo para avaliação da produção de ouriços e castanhas (amêndoas) foram registradas, plaqueadas e medidas, nos 6 ha da Reserva Leste de Castanheiras do Platô Almeida, 84 árvores, gerando uma abundância excepcionalmente alta de 14 castanheiras/ha.

A amplitude diamétrica foi de 48 a $226 \mathrm{~cm}$, enquanto o diâmetro médio foi de $122 \mathrm{~cm}$. As classes modais são as de 100 a $109,9 \mathrm{~cm}$ e 110 a $119,9 \mathrm{~cm}$, ambas com 13 árvores cada; 54,8\% das árvores têm diâmetros inferiores a $120 \mathrm{~cm}$. Quatro castanheiras apresentaram diâmetros superiores a $200 \mathrm{~cm}$ (Figura 4).

$\mathrm{Na}$ avaliação da safra de castanha do ano de 2003, ficou evidenciado que do total de 84 árvores, 74

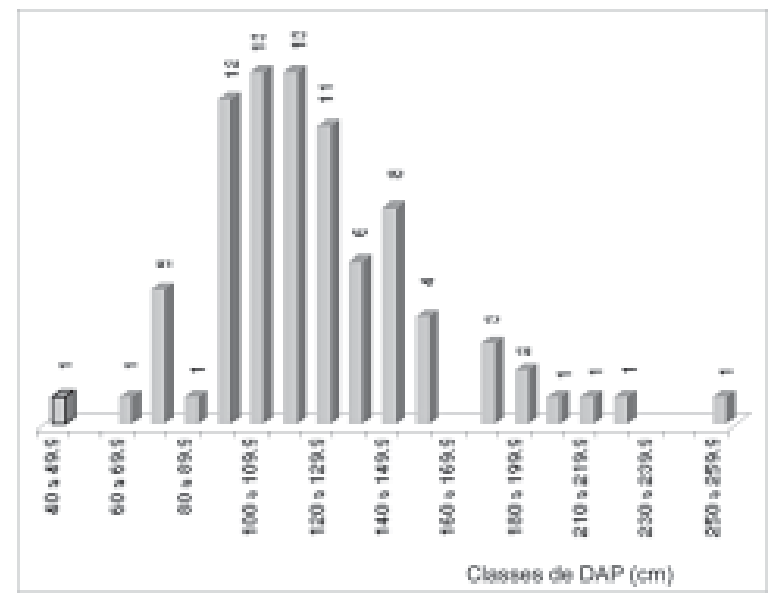

Figura 4. Distribuição em classes diamétricas das 84 castanheiras da floresta ombrófila densa monitoradas na Reserva Leste de Castanheiras do Platô Almeidas, Flona Saracá-Taqüera/lbama, Porto Trombetas, Oriximiná, Pará. produziram frutos. A produção variou de 1 a 172 ouriços por castanheira, com média de 29 ouriços/ castanheira e peso médio de 673 g. A média de amêndoas por ouriço foi de 16 castanhas e o peso médio unitário foi de $7 \mathrm{~g}$. A produção média foi de 477 castanhas/árvore produtiva.

No sentido de se ter uma referência da atividade castanheira na região foram feitas entrevistas com vários castanheiros. Sintetizando os dados colhidos em Porto Trombetas, observa-se que são coletados por 30 pessoas em uma área de coleta de castanhas, $800 \mathrm{hl} \mathrm{(1} \mathrm{hl} \mathrm{=} 100$ l), nos meses de fevereiro, março (pico da produção) e abril. Um hectolitro tem $50 \mathrm{~kg}$ de castanha, vendido a base de $\mathrm{R} \$ 2,00 / \mathrm{kg}$. Então, numa safra, colhem-se $40.000 \mathrm{~kg}$. Para cada $200 \mathrm{~kg}$ de castanha são retirados $30 \mathrm{~kg}$ para consumo familiar, resultando um total de $6.000 \mathrm{~kg}$ para dividir entre 30 coletores, ou seja, $200 \mathrm{~kg}$ para cada. Considerando-se, então, os 34.000 kg restantes para comercialização, apura-se com a venda $R \$ 68.000,00$ que, divididos pelos 30 trabalhadores, totalizam $\mathrm{R} \$ 2.267,00$ por trabalhador para os três meses de serviço, o que renderia $\mathrm{R} \$ 756,00$ por mês para cada trabalhador se a divisão fosse linear, o que não acontece. Desse valor mensal o coletor recebe menos de $40 \%$, próximo de $\mathrm{R} \$ 300,00 /$ mês.

No ano de 2001, segundo o Instituto Brasileiro de Geografia e Estatística (IBGE) (2004), o Brasil produziu 6.266 t de castanhas, comercializadas ao preço de $R \$ 4.128 .000,00$ (média de $R \$ 0,66 / \mathrm{kg}$ ), enquanto em 2000 foram $33.431 \mathrm{t}$ ao preço de $R \$ 18.556 .000,00$ (média de $R \$ 0,56 / \mathrm{kg}$ ). Considera-se que essas cifras estão muito subdimensionadas, pois, em sendo verdadeiras, e considerando como maior valor aquela produção de Porto Trombetas, citada anteriormente (34.000 kg), renderiam $\mathrm{R} \$ 22.440,00$ no total, ou seja, seguindo aquele raciocínio cada coletor apuraria $\mathrm{R} \$$ 99,73 por mês, o que inviabiliza a atividade.

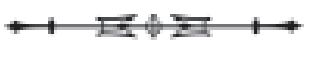




\section{CONCLUSÃO}

A castanheira, plantada na Amazônia setentrional em áreas degradadas pela mineração, através de reflorestamentos heterogêneos, é uma espécie de comprovada adaptabilidade e excelente crescimento.

Uma seleção de matrizes, inclusive nas áreas reflorestadas, possibilita a obtenção de árvores com c.a. $60 \mathrm{~cm}$ de diâmetro e $28 \mathrm{~m}$ de altura, aos 19 anos, ou seja, incremento médio anual do crescimento diamétrico superior a $3 \mathrm{~cm} / \mathrm{ano}$ e de altura próximo de 1,5 m/ano.

A produção de mudas de castanheiras clonadas (enxertadas) com material proveniente das castanheiras mais desenvolvidas do reflorestamento de 1984 representa uma boa estratégia para os reflorestamentos futuros que visem à recuperação de áreas degradadas pela empresa.

A safra de castanha relativa ao ano de 2003, na Reserva Leste do Platô Almeidas, foi muito reduzida, daí a necessidade de acompanhar essa produção por um período mínimo de 5 ou 6 anos. Caso confirmada essa produção nas próximas safras podese atribuir tal fato, entre outros, à fragmentação da floresta e, consequentemente, talvez na virtual ausência dos principais agentes polinizadores da espécie, aos himenópteros do gênero Bombus.

\section{AGRADECIMENTOS}

À Mineração Rio do Norte S.A. e ao Ibama/MMA, gestor da Flona Saracá-Taqüera.

\section{REFERÊNCIAS}

BENTES, R. S.; MARIN, R. A.; EMMI, M. F. 1988. Os cemitérios das castanheiras do Toncantins. Pará Desenvolv., Meio Ambientes, Belém, v. 23, p. 18-23, jan./jun.

CAMARGO, P. B. et al. 1994. How old are large Brazil-nut trees (Bertholletia excelsa) in the Amazon? Scientia Agricola, v. 51, p. 389-391.

CAMPBELL, D. G. et al. 1986. Quantitative ecological inventory of terra firme and várzea tropical forest on the Rio Xingu, Brazilian Amazon. Brittonia, Ney York, v. 38, n. 4, p. 369-93.
CARPANEZZI, A. A. et al. 1990. Espécies pioneiras para recuperação de áreas degradadas: a observação de laboratórios naturais. In: CONGRESSO FLORESTAL BRASILEIRO, 6., Campos do Jordão. Anais... Campos do Jordão: SBS/SBEF. p. 216-221.

CAVALCANTE, P. B. 1988. Frutas comestíveis da Amazônia. Belém: Museu Paraense Emílio Goeldi. p. 82-84. (Col. Adolpho Ducke). DUCKE, A.; BLACK, G. A. 1954. Notas sobre a fitogeografia da Amazônia brasileira. Bol. Téc. Inst. Agron. Norte, Belém, v. 29, p. 1-62.

FRANCO, A. A.; et al. 1992. Revegetação de solos degradados Seropédica: Embrapa/Cnpab. 11 p. (Comunicado Técnico, 9)

IBGE. 2004. Fundação Instituto Brasileiro de Geografia e Estatística. Disponível em: < http//www.ibge.gov.br/home/estatistica/indicadores/ agropecuaria/spa/defaut.shtm>

JESUS, R. M. 1997. Restauração florestal na Mata Atlântica. In: SIMPÓSIO NACIONAL DE RECUPERAÇÃO DE ÁREAS DEGRADADAS, 3., Ouro Preto. Anais... Ouro Preto: SOBRADE/ UFV. p. 544-557.

KITAMURA, P. C.; MULLER, C. H. 1984. Castanhais nativos de Marabá-PA: fatores de depredação e bases para sua preservação. Belém: Embrapa. p. 1-32. (Documentos Embrapa/Cpatu, 30).

LAPA, R. P. 2000. A bauxita e o rejeito da bauxita. In: BOZELLI, R. L.; ESTEVES, F. A.; ROLAND, F. (Ed.). Lago Batata: impacto e recuperação de um ecossistema amazônico. Rio de Janeiro: IB-UFRJ/ SBL. p. 27-5.

LEÃO, N. V. M.; OHASHI, S. T.; VIEIRA, I. C. G. 2004. Tha de germoplasma da Hidrelétrica de Tucuruí: uma reserva da biodiversidade para o futuro. Tucuruí: Eletronorte. 119 p. Relatório Técnico.

LEWIS, R. R. 1982. Mangrove forests. In: Ed: Lewis, R. R. Creation and restoration of cosatal plant. Boca Raton, Florida: CRC Press. p. 154-71.

MORITZ, A. 1984. Estudos biológicos da floração e frutificação da castanha-do-Brasil. Belém: Embrapa/Cpatu. p. 1-78. (Documentos Embrapa, 29).

MOSCATELLI, M.; DE'CARLI, C.; ALMEIDA, J. R. 1993. Legalidade teórica e realidade prática na defesa de manguezais: estudo de caso em Angra dos Reis, Rio de Janeiro. In: SIMPÓSIO DE ECOSSISTEMAS DA COSTA BRASILEIRA SUBSÍDIOS A UM GERENCIAMENTO AMBIENTAL, 3., São Paulo. Anais... São Paulo: [s.n.]. p. 93-8.

MULLER, C. H.; et al. 1980. Castanha-do-Brasil: resultados de pesquisa. Belém: Embrapa/Cpatu, p. 1-25. (Miscelânia, 2).

PEREIRA, I. C. V.; COSTA, S. L. L. 1981. Bibliografia de castanhado-Brasil (Bertholletia excelsa H.B.K.). Belém: EMBRAPA/ CPATU. 192 p.

PERES, A. P. et al. 2003. Demographic Threats to the Sustainability of Brazil Nut Exploitation. Science, v. 302, p. 2112-4.

PIRES, J. M. 1973. Tipos de vegetação da Amazônia. Publ. Avulsa Mus. Pará. Emílio Goeldi, Belém, v. 20, p. 179-202.

PIRES, J. M. 1976. Aspectos ecológicos da floresta amazônica. In: CONGRESSO BRASILEIRO DE FLORESTAS TROPICAIS, 2., Anais... Mossoró: [s.n.]. (Col. Mossoroense, 65).

RADAMBRASIL. 1976. Santarém. p. 310-414. v. 10. Projeto RADAMBRASIL. Folha SA.21.

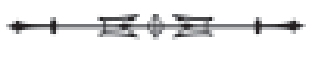


RADAMBRASIL. 1974. Belém: vegetação. DNPM. Projeto RADAMBRASIL. Levantamento de Recursos naturais. v. 5. Folha AS 22 RODRIGUES, R. R.; GANDOLFI, R. 1996. Recomposição de florestas nativas: princípios gerais e subsídios para uma definição metodológica. Rev. Bras. Horto. Orn., v. 2, n. 1, p. 4-15.

SALOMÃO, R. P.; SILVA, M. F. F.; ROSA, N. A. 1988. Inventário ecológico em floresta pluvial tropical de terra fieme, Serra Norte. Carajás, Pará. Bol. Mus. Para. Emílio Goeldi, sér. Bot., Belém, v. 4, n. 1, p. 1-46.

SALOMÃO, R. P. 1989. Composição florística e a fitossociologia de floresta pluvial de floresta pluvial tropical de terra firme, Município de Marabá, Estado do Pará. Bol. Mus. Pará. Emílio Goeldi, sér. Bot., v. 7, n. 1.

SALOMÃO, R. P. 1991. Estrutura e densidade de Bertholletia excelsa H. \& B. ("Castanheira") nas regiões de Carajás e Marabá, Estado do Pará. Bol. Mus. Para. Emílio Goeldi, sér Bot., Belém, v. 7, n. 1, p. 47-68.

SALOMÃO, R. P. et al. 1997. Uso de parcelas permanentes em reflorestamentos de diversas idades para avaliação da recuperação de áreas mineradas, Porto Trombetas, Oriximiná, Pará. In: SIMPÓSIO NACIONAL DE RECUPERAÇÃO DE ÁREAS DEGRADADAS,3. Anais... Viçosa: DEF/UFV. p. 407-415.

SALOMÃO, R. P. 1998. Monitoramento de florestas plantadas primárias. Porto Trombetas: Mineração Rio do Norte. 54 p. (Relatório Técnico Anual MRN / TSA, 3).

SALOMÃO, R. P.; ROSA, N. A. 2000. Aptidão ecológica de espécies arbóreas amazônicas para a recuperação de áreas degradadas pela mineração de bauxita, Porto Trombetas, município de Oriximiná, Pará - $1^{\text {a }}$ Aproximação. In: SIMPÓSIO NACIONAL DE RECUPERAÇÃO DE ÁREAS DEGRADADAS, 4., Blumenau. Anais... Sobrade:Urb. 1 CD-ROM.

SALOMÃO, R. P.; ROSA, N. A.; MATOS, A. 2000. Monitoramento da floresta tropical primária visando a restauração da paisagem florestal em áreas degradadas da Amazônia brasileira. In: SIMPÓSIO NACIONAL DE RECUPERAÇÃO DE ÁREAS DEGRADADAS, 4., Blumenau. Anais... Sobrade: Urb. 1 CD-ROM.

SALOMÃO, R. P. et al. 2002. Inventário florestal em 772,25 ha de castanheiras (Bertholletia excelsa H. \& B. Lecythidaceae) no Platô Almeidas, Floresta Nacional Sarcá-Taqüera/IBAMA, Porto Trombetas, município de Oriximiná, Pará. Porto Trombetas, Pará: Mineração Rio do Norte. 100 p. Relatório Técnico.

SALOMÃO, R. P.; MATOS, A. H.; ROSA, N. A. 2002. Dinâmica de reflorestamentos visando a restauração da paisagem florestal em áreas de mineração na Amazônia. Bol. Mus. Para. Emílio Goeldi, sér. Bot., Belém, v. 18, n.1, p. 157-194.

VIANA, V. M. 1990. Biologia e manejo de fragmentos de florestas naturais. In: CONGRESSO FLORESTAL BRASILEIRO, 6., Campos do Jordão. Anais ... Campos do Jordão: [s.n.]. p. 219-21.

VIEIRA, I. C. G. et al. 1996. O renascimento da floresta no rastro da agricultura. Ciência Hoje, v. 20, n. 119, p. 38-44.

WANDELLI, E.V. et al. 1997. Sistemas agroflorestais: uma alternativa para a recuperação de áreas degradadas na Amazônia ocidental. In: SIMPÓSIO NACIONAL DE RECUPERAÇÃO DE ÁREAS DEGRADADAS, 3., Ouro Preto. Anais... Viçosa: DEF / UFV. p. 487-493. 